\title{
UM MUSEU MEFISTOFÉLICO MUSEOLOGIZAÇÃO DA MAGIA NEGRA NO PRIMEIRO TOMBAMENTO ETNOGRÁFICO NO BRASIL
}

Alexandre Fernandes Corrêa (UFRJ)

Neste artigo, apresentamos uma reflexão sobre as significativas improvisações museológicas manifestas desde o processo de tombamento da Coleção Museu de Magia Negra do Museu da Polícia Civil do Rio de Janeiro (1938). Trata-se de um estudo sobre o pensamento social e o imaginário literário brasileiro, relacionado ao tema da magia no século XX.

PATRIMÔNIO CULTURAL; MUSEOLOGIA; LITERATURA; MAGIA; MODERNISMO.

CORRÊA, Alexandre Fernandes. Um museu mefistofélico: museologização da magia negra no primeiro tombamento etnográfico no Brasil. Textos escolhidos de cultura e arte populares, Rio de Janeiro, v.11, n.1, p. 33-51, mai. 2014. 


\section{A MEPHISTOPHELIC MUSEUM \\ THE MUSEUMIZATION OF BLACK MAGIC IN THE FIRST ETHNOGRAPHIC SAFEGUARDING IN BRAZIL}

Alexandre Fernandes Corrêa (UFRJ)

This article reflects upon significant museum improvisations evident from the process of safeguarding of the Collection Museum of Black Magic from the Museum of the Civil Police of Rio de Janeiro (1938). This is a study of the Brazilian social thought and its literary imagination in relation to the theme of magic in the twentieth century.

CULTURAL HERITAGE; MUSEOLOGY; MODERNISM; LITERATURE; MAGIC.

CORRÊA, Alexandre Fernandes. Um museu mefistofélico: museologização da magia negra no primeiro tombamento etnográfico no Brasil. Textos escolhidos de cultura e arte populares, Rio de Janeiro, v.11, n.1, p. 33-51, mai. 2014. 


\section{ANTROPOLOGIA DO OLHAR ${ }^{1}$}

Pensar é um ato que põe em dúvida a estrutura de tudo.

O Diabo Pensativo.

Dante Milano.

Este estudo é resultado do exercício de uma modalidade de pesquisa baseada na antropologia dos olhares sobre a Coleção-Museu de Magia Negra do Rio de Janeiro; no qual relativizamos as diferentes concepções acerca dos diversos estatutos museológicos imputados a esse acervo. Com esse intuito operamos procedimentos interpretativos apoiados na prática antropológica apresentada por Claude Lévi-Strauss(1986) na obra O olhar distanciado. O antropólogo francês resumiu, em entrevista concedida em 1998, seu empreendimento metodológico:

O olhar distanciado caracteriza o olhar antropológico. A expressão 'olhar distanciado' é de Hami, que foi um grande ator dramático japonês. Ele dizia que, para ser um bom ator, era preciso olhar para si mesmo, o tempo todo, com os olhos afastados do espectador. $\mathrm{O}$ olhar distanciado pode ser aprendido através de treinamento, mas também é algo que se pode possuir desde o nascimento, uma espécie de característica da personalidade de cada um. ${ }^{2}$

Através desse método de observação e descrição dos diferentes olhares e concepções sobre os estatutos museológicos da Coleção de Magia Negra do Museu da Polícia Civil, tombada pelo Iphan em 1938, investigamos o significado cultural desse acervo heteróclito que compõe o panteão do patrimônio cultural brasileiro contemporâneo.

São diversos olhares que pretenderam enquadrar na história o significado dessa coleção museológica, classificada e inscrita como o primeiro patrimônio etnográfico do país. Assim, colocamos sob as coordenadas de um quadro sinótico o olhar da Polícia Civil do antigo Distrito Federal e do Judiciário; o olhar dos agentes de patrimonialização, da Academia Sphan; o olhar dos poetas e literatos modernistas; o olhar dos detetives e peritos da Polícia Civil e por fim o olhar dos antropólogos que a pesquisaram a partir de meados da década de 1970. A confluência relativizadora desses olhares demonstrou que o enquadramento exclusivo em apenas um desses olhares, reduz o alcance cultural e patrimonial desse acervo cultural heterodoxo. A última tentativa de estabelecer seu estatuto museológico como acervo afro-brasileiro parece restringir seu prisma sociocultural, pela falta de contextualização no imaginário social modernista, em formação naquelas primeiras décadas do século XX no Brasil.

O ensaio crítico que resultou de duas pesquisas de pós-doutorado (coRRÊA, 2006; 2010) sobre a coleção-museu em foco propõe nova hipótese original. 
Após o encontro com a biografia fascinante do poeta carioca Dante Milano, primeiro diretor do Museu da Polícia Civil do Rio de Janeiro, entendemos que esse acervo se encontrava, na verdade, entre processos culturais muito mais complexos e que era preciso alargar nossa compreensão sobre o significado cultural dessa singular coleção museológica.

Todavia, antes de seguir na apresentação da hipótese que conduziu à reflexão e à construção do ensaio referido, do qual este artigo é uma breve introdução condensada, gostaríamos de convidar o leitor a conhecer os dados e as coordenadas que o ajudarão a se localizar no tempo e no espaço, para, a partir de metaponto de vista, formular autonomamente novo olhar sobre a coleção museológica estudada.

\section{MUSEU DA POLÍCIA CIVIL DO RIO DE JANEIRO}

Observando o mapa de localização topográfica do Centro da Cidade do Rio de Janeiro, o Museu da Polícia Civil encontra-se na região entre o Largo da Carioca, a Catedral Católica e a Praça da República. Está estabelecido, mais exatamente, ao lado da sede oficial da Polícia Central. ${ }^{3}$ Atualmente essa região passa por processo de gentrification e valorização imobiliária intensa, que promete o revigoramento e a revitalização da área urbana sem precedentes. Todavia, a referência a esse acervo não se encontra presente em nenhum material de divulgação turística da "cidade maravilhosa"; nem mesmo contamos com algum city tour mais alternativo incluindo visita a essa coleção de magia negra ou ao próprio Museu da Polícia Civil. ${ }^{4}$

O Instituto do Patrimônio Histórico e Artístico Nacional (Iphan/MinC) tem relação histórica extremamente ambivalente com esse acervo. O cidadão que pretenda encontrar a direção e o acesso a esse equipamento cultural terá muita dificuldade. Além do mais, a própria Polícia Civil mantém há alguns anos parte do acervo da "magia negra" em "reserva técnica" e não há notícia de abertura integral ao público. No momento o prédio está em processo de reforma, após as intensas chuvas de abril de 2010 e os abalos de uma obra da Petrobras realizada no entorno do prédio, que danificou suas estruturas. Diante de todas essas adversidades, pode-se imaginar as dificuldades de ter acesso ao conjunto de peças e objetos, mesmo para pesquisadores credenciados, impossibilitados de obter acesso livre a esse bem cultural tombado, a não ser por fotografias dispersas em diferentes publicações. As possíveis hipóteses para esse comportamento adverso, que em muitos aspectos parecem constituir verdadeiro tabu institucionalizado, serão apresentadas no decorrer deste texto. Antes é preciso algumas palavras sobre a história do Museu da Polícia Civil. 
Observando fotos ilustrativas do exuberante palácio, vemos destacar-se o estilo eclético francês em pleno auge do triunfante positivismo republicano. Reflete, com sua arquitetura simulada da Belle Époque francesa, as pretensões modernizadoras e improvisadas no país recém-introduzido no rol das repúblicas ocidentais. Nesse cenário de promessas racionalizadoras e cientificistas, esse edifício acabou por tornar-se o local em que aconteceram os fatos mais atrozes da história moderna brasileira. Nesse prédio funcionou em plena ditadura militar dos anos 64-85 o antigo Departamento de Ordem Política e Social (Dops). A memória que ali ainda está parcialmente encoberta aglutina e preserva agonias que aguardam a revelação oportuna de seus segredos; trabalho que tem sido levado a cabo pela Comissão da Verdade. ${ }^{5}$

Entretanto, aguardamos o tempo em que se poderá observar a coleçãomuseu sem estar sujeitos às admoestações das autoridades, tanto policiais como patrimoniais. Muito poderia ser dito sobre os comportamentos idiossincráticos que diferentes personalidades têm expressado em relação a esse complexo sociocultural patrimonializado no final da década de 1930. Porém, temos que ser econômicos neste texto e nos limitarmos a seguir aqui na apresentação das particularidades desse interessante complexo museológico.

\section{MUSEOLOGIZAÇÃO DO CRIME}

Nas salas do prédio, em que hoje se preserva de um modo improvisado e amador a memória de períodos ditatoriais recentes na história brasileira, funcionou a Academia de Polícia. Nesse edifício eram ministradas as aulas do Prof. Elísio de Carvalho, em 1912. Sob a batuta do mestre criminalista foram realizadas sessões didáticas de polícia científica para as novas turmas de policiais do Distrito Federal. Como novo equipamento que serviria de suporte pedagógico para a Academia recém-fundada, foi proposta a criação de um Museu do Crime; utilizado desde então como suporte museológico e cenográfico para a preservação improvisada de cenas de crimes, delitos etc., além de depósito das ações de apreensão judicial e perícia.

O Museu da Polícia foi lugar de guarda e apreensão, coleta e reserva dos materiais e objetos recolhidos em 'batidas' policiais, investigações e ações judiciais na capital do país. Após o decreto de 1934, editado pelo Gabinete de Segurança Pública, definiram-se as competências das quatro delegacias auxiliares relacionadas diretamente com aquisição do acervo que integraria o futuro Museu da Polícia. Pela natureza de suas atribuições, são objeto de nosso interesse aqui, uma vez que parte considerável do acervo, hoje pertencente ao Museu da Polí- 
cia, origina-se de suas atuações. Assim, cabia à Primeira Delegacia Auxiliar, entre 1934 e 1945:

I - Processar a cartomancia, mistificações, magias, exercício ilegal da medicina e todos os crimes contra a Saúde Pública;

II - Ter sob sua vigilância o meretrício, providenciando contra ele, sem prejuízo do processo judicial competente, da forma que julgar mais conveniente ao bem da população e da moralidade pública;

III - Reprimir e processar o proxenetismo e o caftismo;

IV - Fiscalizar as delegacias distritais do $1^{\circ}$ ao $10^{\circ}$ distrito policial, providenciando para que nelas o serviço se faça com toda responsabilidade.

Todo esse conjunto de ações policiais contribuiu para a criação de um acervo repleto de curiosidades, mas que infelizmente sofreu durante longo tempo, pela força do abandono, desgaste comprometedor em muitos aspectos, deixado em lamentável estado de indiferença e negligência.

\section{CENOGRAFIA DO MUSEU DA POLÍCIA NA DÉCADA DE 1970}

Gostaríamos de destacar dessa cronologia histórica um período importante pelo qual passou a referida coleção museológica, na década de 1970, quando o Museu da Polícia ficou instalado temporariamente na Rua Frei Caneca. Observamos que a cenografia produzida no espaço oferecido para o funcionamento provisório do Museu ofereceu elementos notáveis para interpretação. Foi relatado, em documento de pesquisa elaborado pela equipe do convênio Funarte/ CNDA, ${ }^{6}$ o assombro em relação ao ambiente. Chegou-se a afirmar que a miseen-scène escolhida, montada por um detetive de formação umbandista, configurava uma atmosfera "surrealista", num cenário que oscilava entre o naïf, o kitsch e o trash.

Nesse período a coleção possuia acervo mais amplo e diversificado. Mas em 1989 sofreu lamentável incêndio, que foi avassalador, ocasião em que mais de 40 peças sucumbiram e arderam sob o poder do fogo. Peças e objetos tombados desapareceram, e outras peças e objetos incorporados a posteriori também se perderam. Entre as peças desaparecidas destaca-se o Exu Sete Capas, figura impressionante que tinha grande destaque no meio do salão central do Museu improvisado. ${ }^{7}$

Como se vê, o conjunto do acervo museológico estudado compõe-se de um complexo reunindo as seguintes coleções: de Armas Brancas; de Toxicologia; de Jogos de Azar; de Objetos de Magia; e do Museu da Magia Negra. No ensaio que resultou desse trabalho de investigação, apresentamos as particularidades 
de cada uma dessas coleções. No momento, cabe considerar que esse complexo cultural e museológico, para ser compreendido plenamente, exige esforço de contextualização que deve ser executado com sensibilidade alargada.

\section{ARTE \& CIÊNCIA MODERNA: PROCESSO DE “DISTABUZAÇÃO”}

É necessário nos aproximar um pouco mais do ponto central da argumentação. Apresentada a localização e as características do acervo, devemos avançar na introdução dos referenciais teóricos que propiciaram desenhar as coordenadas dos diferentes olhares sobre esse acervo. Para tal análise nos debruçamos sobre um novo mapa histórico-cultural, no qual foram cartografadas as posições de atravessamento semiológico da Coleção Museológica da Magia. Assim temos:

\section{Literatura \& Poesia}

Nesse ponto cardeal procuramos descrever as linhas principais do modernismo literário do imaginário social brasileiro, tendo como pano de fundo mais amplo o modernismo como fenômeno civilizacional ocidental, da maneira como Marshall Berman (1986) tratou na obra Tudo que é sólido desmancha no ar. Outro texto importante que guiou este trabalho com o fito de atingir as profundezas de uma sociologia do imaginário modernista, foi o livro $A$ experiência etnográfica de James Clifford (1998).

Com base nesses textos interpretativos de ampla abordagem interdisciplinar podemos estabelecer um olhar metaetnológico e metassociológico que superasse os impasses de um reducionismo etnicista que limitava o significado cultural dessa coleção ao modismo "étnico" dominante na atualidade. Esse modismo do elogio desenfreado e sintomático da "diferença étnica" acabou tornando-se um obstáculo epistemológico importante, que mereceu longo esforço de superação. A ideologia "etnicista" tornou-se um viés difícil de contornar, pois a coleção de "magia negra" em foco enquadrava-se facilmente nas idéias dominantes nessa área. Mas, com o auxílio desses textos relativizadores, conseguimos desenvolver interpretação mais alargada do significado cultural de acervo cultural. Além do signo de peças e objetos considerados e classificados como afro-brasileiros, católicos, cristãos, europeus, indígenas, etc., compreendemos que o conjunto museológico ao qual dedicávamos atenção era atravessado por linhas do imaginário que jamais poderiam se restritas e reduzidas a um suporte étnico exclusivo. Tratava-se então de procurar atingir as camadas mais profundas nos seus lastros subjacentes, que confirmassem a importância desse legado e dessa herança cultural, para além do nicho etnológico a que eventualmente se via condenada a ser estigmatizada e negligenciada. A recuperação dos vínculos mais profundos e inconscientes dessas linhas do imaginário modernista foi fundamental para o avan- 
ço da reflexão. É nesse sentido que resplandece o achado antropológico mais importante, produzido por este trabalho, na verdade nossa contribuição original para essa pesquisa, ao trazer para os estudos sobre a patrimonialização da "magia", uma nova abordagem. Referimo-nos especificamente à análise da obra poética de Dante Milano. A descoberta dessa personagem herética e heterodoxa, como a própria coleção, abriu a porta para os meandros mais ocultos, revelando os significados encobertos pela leitura rápida e apressada, feita até então pelos especialistas. Decidimos, a partir de então, fazer uma arqueologia do imaginário literário desse poeta carioca, afinal de contas o primeiro diretor do Museu da Polícia Civil do Rio de Janeiro e, mais importante ainda, o autor dos ofícios de encaminhamento do processo de tombamento da Coleção-Museu de Magia Negra pelo antigo Sphan, em 1938.

O trabalho arqueológico realizado acabou por fazer emergir dois literatos de importância universal. Dante Milano foi tradutor das obras de Dante Alighieri e de Charles Baudelaire. Na consulta da obra do poeta carioca, considerado um dos cinco maiores poetas modernistas brasileiros - infelizmente ainda pouco conhecido -encontramos um legado literário de importância capital para a interpretação antropológica da coleção aqui estudada. Aspectos desse trabalho interpretativo são mais aprofundados em textos publicados em periódicos especializados (Corrêa, 2012; 2013).

\section{Magia na Arte Moderna}

O trabalho de arqueologia do imaginário modernista avançou em outras direções complementares. Após visitar a obra clássica $A$ divina comédia, e em seguida revisitar o poeta simbolista de As flores do mal, nos aproximamos do dadaísmo, do surrealismo e do cubismo. Citamos ainda, mais particularmente, Jean Arthur Rimbaud (1854-1891), Une saisson en enfer; Tristan Tzara (1896-1963); André Breton (1896-1966) nos seus manifestos de 1923 e 1924; e, Pablo Picasso, especialmente no designado 'período africano'.

\section{Ciências Sociais e a questão do método: Gilberto Freyre}

Mas era preciso ir mais além. Foi quando, ao voltar nosso olhar para o modernismo brasileiro, encontramos outra fonte segura. Tratava-se de Gilberto Freyre. Com suas próprias palavras, entregamos ao leitor a justa medida de sua importância para o trabalho semiológico aqui empreendido. Como ele mesmo afirmou, seu método de trabalho consistia no que designou "metodologia unitária", isto é, a:

síntese ou combinação de métodos semelhantes à que vem empregando Mestre Pablo Picasso em artes plásticas (...) fusão dos mé- 
todos analítico e orgânico de interpretação do homem, para dessa fusão resultar uma imagem quanto possível completa do humano. Pois parece que essa imagem (...) só se obtém tendo em vista, no estado do homem, o que nesse homem é considerado 'primitivo', junto com a sua denominada 'civilização'. Assim se caminharia para uma metodologia unitária, na Antropologia ou nos estudos sociais de base antropológica, que transbordasse em reinterpretações artísticas e filosóficas do homem (FREYRE, 1963, p.61).

As artes e as ciências modernas avançaram nesse trabalho de "distabuzação" que culminou em profundas conquistas, resultando em obras-primas de valor universal. Todo esse processo sofreu resistências reativas que se expressaram no nazismo e fascismo. Porém, após a Segunda Grande Guerra, com o processo acelerado de descolonização da África, ocorreu novo impulso que coincide com a independência de diversos países locais das metrópoles europeias.

\section{OLHAR POÉTICO: O MODERNISTA MARGINAL}

No entanto, o trabalho de contextualização histórico-cultural não foi suficiente, foi preciso atingir os traços mais profundos da singularização na análise do modernismo brasileiro. Assim, nossa pesquisa chega ao clímax quando se abre para a vida e obra de Dante Milano: o 'modernista marginal' em função das características de sua produção literária, expressas no seu "antilirismo sinistro, fantasmagórico e visionário". Como já comentado, D. Milano foi o primeiro diretor do Museu da Polícia Civil do Distrito Federal, entre 1945 e 1956. Mas, além disso, juntos dos amigos desde a década de 1920, participou de um movimento fecundo de renovação da arte moderna brasileira. Ele e seus amigos da boêmia na Lapa carioca - tais como Villa-Lobos, Ribeiro Couto, Cândido Portinari, Jaime Ovalle e Manuel Bandeira - revolucionaram e atualizaram o 'relógio' cultural do país.

Nesse sentido de perscrutação de uma obra literária e poética de valor extraordinário, arriscamos aplicar a hipótese de trabalho apresentada por Hermano Vianna (1995), no seu estudo Mistério do samba. Trata-se da hipótese da "distabuzação": processo que ele identificou no samba e que aqui nós empregamos no contexto da magia. É verdade que essa intuição teórica nasceu da fonte de Gilberto Freyre, como o próprio Vianna confessa em sua obra. Destarte, o que nos faz lançar mão dessa chave interpretativa também é sugerido por influências de outras fontes, como a filosofia. É quando resplandece as seguintes orientações interpretativas: "O mal não é cósmico ou ontológico, é histórico e contingente" (RICOEUR, 1950, p.30). E: "O mal não é criado por nós nem pelos outros, nasce do tecido que fiamos entre nós" (MERLEAU-PONTY, 1981). Como se vê, essas referên- 
cias nos oferecem uma ampliação do alcance interpretativo, ultrapassando reducionismos etnicistas hoje tão glorificados, nos lançando numa análise simbólica mais generosa e universalista, pois invoca a dimensão mitológica e o inconsciente social literário e modernista (CORRÊA, 2009).

\section{OLHAR MEFISTOFÉLICO: TEATRO DO BEM E DO MAL}

É desse escopo amplificado de possibilidades interpretativas que a análise avançou. Tomando como ponto de partida o imaginário literário brasileiro do início do século XX, nos deparamos com um poema "libertino" impressionante, que sinaliza para a força da feitiçaria, da magia e da bruxaria no imaginário estético moderno: Macumba do pai Zusé: Na Macumba do Encantado/Nego velho paide-santo fez mandinga./No Palacete de Botafogo,/Sangue de branca virou água./ Foram ver: estava morta. (BANDEIRA, 1930). Nesse trajeto, continuamos o trabaIho de escavação das linhas de força do imaginário modernista, já que sua pertinência se comprova nos registros indicados.

\section{Visão do Paraíso \& do Inferno}

Como escreveu Sérgio Buarque de Holanda (2000, p. XVII): “Uma das missões do historiador consiste em procurar afugentar do presente os demônios da História". Nesse caminho aberto por intérpretes desbravadores, encontramos Michel de Certeau, recuperando substratos culturais importantes. Como sabemos, esse autor:

não hesitou em apontar o século XVI e os primeiros sessenta anos do século XVII como os períodos mais satânicos da Europa Cristã. Foi nesse contexto, envolta em uma densa aura de satanismo, que a Cristandade europeia aportou em solo americano, pronta a detectar e combater rastros da malignidade diabólica para além do Atlântico singrado (CHAIN, 2003, p.85)

Dessarte, esse trabalho arqueológico foi revelando camadas mais recentes, mais próximas de nossa modernidade, estendendo a força de uma estrutura antropológica que se alastra pela história e chega até a virada de nosso século, forte e pulsante.

\section{As Artes Mágicas}

A dialética do bem e do mal já produziu imagens literárias e mitológicas importantes, desde o Livro de Jó, da Bíblia Sagrada. Porém, nessa linha de descortinar as trilhas modernas outra fonte importantíssima brilha no horizonte da literatura universal, apresentando-se como chave interpretativa de grande força heurística, constituindo ferramenta semiológica poderosa. Trata-se da obra máxi- 
ma da civilização ocidental, Fausto, de Goethe (1952). ${ }^{8}$ A saga dessa personagem extraordinária sintetiza de modo penetrante o cerne dos conflitos existenciais básicos do drama psicológico e filosófico e estrutural do "admirável novo mundo" cultural burguês. As "estruturas antropológicas" fundamentais que sustentam a modernidade ali se encontram desenhadas de maneira contundente. É assim que, de posse desse arsenal teórico, pudemos compreender de modo satisfatório, os signos que se revelaram a partir de nossa pesquisa em culturanálise.

\section{Encenação do Diabólico e do Satânico}

Convém salientar que a referência ao signo de "mefistófeles", não é um recurso interpretativo acrobático. O signo de "mefisto" aparece na lista de inventário enviada para o antigo Sphan, solicitada por Rodrigo de Mello Franco de Andrade. No item número 2, encontramos descrito: “Estatueta de Mefistófeles (Eixu) entidade máxima da linha de malei". ${ }^{9}$ Infelizmente essa estatueta foi definitivamente perdida no incêndio de 1989. Contudo, curiosamente, anos mais tarde, vai ser incorporada à coleção outra figura em que se reafirma a presença dessa personagem 'transcultural'. Vejamos a descrição feita na ficha identificatória do famigerado Exu das Sete Capas, que passou a compor a cenografia do museu:

Esta representação de Exu é típica influência do cristianismo no culto Afro-Brasileiro. Todavia, há um sentido oblíquo de interpretação: enquanto para o cristianismo representa 'satanás' - indesejável, expulso do paraíso, no culto Afro-brasileiro como Exu, uma espécie de embaixador dos homens junto aos orixás (deuses).

Entendemos que esses dados empíricos são suficientes para convencer os céticos, confirmando que temos nesse conjunto museológico excelente oportunidade de realizar uma verdadeira antropologia profunda do imaginário social do período modernista brasileiro.

\section{RETORNO DO ENCOBERTO: “DES-ETNOGRAFIZAÇÃO” DA ALTERIDADE}

As lições mais importantes de nossa antropologia do olhar podem ser delineadas pelo seguinte trajeto semiológico: ação interpretativa sobre o próprio pesquisador; a pesquisa iniciou-se com uma hipótese etnicista abandonada no decorrer da investigação; o olhar distanciado sobre si mesmo; crítica às concepções e doutrinas "etnistas" contemporâneas; crítica ao viés pejorativo do conceito de "patrimônio etnográfico" na sociedade brasileira; religar-se à missão científica original da antropologia: uma aventura pela "desetnografização" irônica; recolocando em foco a diversidade cultural. Todavia, essa aventura antropológica não se ultrapassa ileso. Como exemplo, chama atenção o alcance inusitado que 
tem a crítica ao etnismo contemporâneo, expresso no desabafo de Antoine Vitez (apud PAVIS, 2003, p.258):

Não gosto que me digam que não posso entender nada dos outros, nem os outros de mim. Tenho horror desta moda que faz as diferenças irredutíveis. Então não compreendo nada das mulheres por que sou homem, dos africanos por que sou europeu? Ao pé da letra, isso me enlouquece. Se devesse pensar nisso, não poderia mais viver.

Uma das consequências mais imediatas desse processo de reflexão é a impressão de que é preciso "desestabilizar a própria noção antropológica de cultura".

Ao assumir uma atitude 'irônica' frente às formas de representação etnográfica, o efeito de sua reflexão é desestabilizar a própria noção antropológica de cultura, tal como esta se configurou ao longo do século XX. Em especial aquelas concepções em que a 'cultura' aparece como uma totalidade integrada no espaço e contínua no tempo, dotada de uma 'identidade' e de fronteiras muito bem definidas, fundada em 'raízes' e portadora de 'autenticidade' (CLIFFORD, 1998, p.11).

Entretanto, para seguirmos na análise da coleção, objeto de nossa atenção, faz-se necessário introduzir ainda mais um nível de relativização; patamar mais profundo da escavação arqueológica empreendida.

\section{É Possível Pensar Isso, a Magia?}

No Prefácio da famosa obra As palavras e as coisas, Michel Foucault (1992, p.5) defende a ideia de que:

no deslumbramento da taxionomia [chinesa], o que de súbito atingimos - o que, graças ao apólogo, nos é indicado como o encanto exótico de um outro pensamento - é o limite do nosso: a impossibilidade patente de pensar isso. Que coisa, pois, é impossível pensar, e de que impossibilidade se trata?

É possível pensar a magia? Como ficamos diante dessa possível impossibilidade? Pode haver um "possível espaço de encontro"? Na antropologia do olhar exercitada neste texto - muito embora atraído pela ironia dessas interrogações vai-se na direção de um tangível "espaço de encontro", do modo como defendia Merleau-Ponty. Para esse filósofo, ao contrário de Foucault, a antropologia leva, sim, a "um alargamento da racionalidade porque desemboca numa ontologia" (MERLEAU-PONTY, 1984, p.200). 


\section{A Crença na Magia}

Porém, ao crer na possibilidade de trabalhar na região dos signos e de exercitar uma verdadeira semiologia, não superamos facilmente todos os obstáculos, num só lance de dados do pensamento. Tivemos também que enfrentar outro obstáculo epistemológico, representados nestas frases lapidares, que sintetizam como em cápsulas nosso dilema sociológico básico: "Nós dependemos do feitiço" (RIO, 1904). "A religião do Diabo sempre existiu entre nós" (RIO, 1951). "O feitiço é uma realidade brasileira. O Brasil vive impregnado de magia" (RAMOS, 1934 [2001]). "O feitiço não seria sobrevivência do arcaísmo na sociedade brasileira. Está no centro mesmo da sua maneira de pensar contemporânea" (MAGGIE, 1992).

Logo, diante de algo tão familiar, a magia, o trabalho de distanciamento e de desnaturalização exigiu sempre, como se pode deduzir, um rigor interpretativo de máxima envergadura; atingiu o pesquisador tal exigência? Cabe à crítica responder.

O entrelaçamento dos domínios do poder e da magia no Brasil é muito forte, como podemos observar em análises diferentes e sutis; como as destacadas acima. Uma interpretação mais recente, porém, iluminou de modo contundente nosso estudo. Num artigo de Norman Gall (2005) vemos o sociólogo estadunidense utilizar o signo de "mefistófeles" para compreender a mais recente desgraça ética do governo central brasileiro, afundado em denúncias de fraudes no famigerado episódio conhecido como mensalão ${ }^{10}$ : reflexão útil para esmiuçar mais um capítulo sobre a natureza demoníaca do poder.

\section{ESTATUTO MUSEOLÓGICO DA COLEÇÃO DE MAGIA NEGRA}

Chegando ao fim de nossa aventura, podemos então apresentar nossa proposta alternativa às concepções reducionistas comumente defendidas para a coleção de magia tombada pelo patrimônio cultural brasileiro. Nosso argumento se apoia em diferentes autores e é herdeiro de influências recentes que buscam integrar uma epistemologia complexa do olhar. Acreditamos que essa coleção, fruto de muitas improvisações e malentendidos - constituindo-se em certos aspectos verdadeiros 'atos falhos' da ação cultural -, pode ser entendida como integrante do mesmo processo sociocultural pelo qual passaram manifestações artísticas e culturais brasileiras, tais como o samba, o bumba-meu-boi, o tambor de crioula, o jongo, etc ${ }^{11}$. 


\section{Performances Culturais}

Do mesmo modo que essas expressões, a magia vem passando por um processo de "distabuzação", na direção de uma "antropofagia" estetizadora e espetaculizadora agenciada por uma nova onda de "turistificação" recente, ${ }^{12}$ isto é, por apropriações simbólicas redutoras de seu valor simbólico e que devoram e canibalizam seu significado original, transformando-a em mais uma mercadoria de fácil consumo pelas classes médias urbanas.

Gilberto Freyre fala de 'uma espécie de cura psicanalítica' de todo país; Gilberto Amado fala em 'distabuzação'. Todas essas expressões tendem a ressaltar o caráter súbito, descontínuo, de descoberta e valorização daquilo que seria 'verdadeiramente' brasileiro, daquilo que antes estava 'tapado' pelo Brasil postiço (VIANNA, 1995, p. 31).

As manifestações culturais e artísticas que antes eram proibidas e reprimidas, hoje estão entronizadas como identidade cultural oficial dos estados e regiões do país. Passaram por processos de esvaziamento de conflitos, de resistências culturais e enfrentamentos latentes, para uma manifestação apaziguadora, teatral, de entretenimento espetacularizado e turistificado.

No diálogo intenso com essas novas mutações no espaço das representações sociais sobre o folclore, os patrimônios culturais e as memórias sociais, o presente estudo propõe um novo olhar sobre a Coleção de Magia Negra: um novo estatuto museológico. Todavia, essa proposta enfrenta variada resistência. O que pode surgir da "hibridização antropofágica" que se processa atualmente, ainda é cedo para afirmar, mas é certo que o impacto mais virulento desse processo de "canibalização" cultural é a ação de "sanitarização" do campo religioso brasileiro, operado pela magia institucionalizada cristã neopentecostal (MARIANo, 1996). A Igreja Universal do Reino de Deus (lurd) e seus neófitos têm promovido ação persecutória contra as manifestações mágico-religiosas afro-brasileiras que afetam diretamente essa coleção de magia, tombada pelo Iphan. Há mais de dez anos a coleção não está exposta integralmente ao público e se vê ainda encoberta sob o manto do obscurantismo "satanizador", que ainda "diaboliza" esse acervo. ${ }^{13}$

A partir da análise semiológica dos diferentes olhares sobre essa coleção museológica, arriscamo-nos a apresentar uma hipótese alternativa e terapêutica. Consideramos que esse acervo merece ser defendido a partir da pluralidade e da polifonia cultural que o marcam de modo significativo. É uma coleção em que encontramos o entrelaçamento de múltiplos olhares sobre a questão da magia, da bruxaria e da feitiçaria na moderna sociedade brasileira - especialmente nas suas 
relações com o Estado; apresentando metamorfoses curiosas, indicando mutações no sentido da formação de uma elaborada e sofisticada "magia de Estado" (TAUSSIG, 1997; 2010): a magia à brasileira!

Após esse denso trabalho de investigação, parece-nos que a coleção museológica em questão coloca em cena a categoria do "mal" na sociedade brasileira, isto é, trata-se provavelmente do primeiro "museu do mal" que dialoga com a museologia do crime, da polícia, das armas, etc: museu do "mal à brasileira". ${ }^{14}$ Dessa forma, ampliamos o campo semântico numa interpretação mais abrangente, atingindo, através da antropologia, um vasto espaço de configuração de seu significado político-cultural. Realçando essas possibilidades interpretativas, pretendemos colocar também em questão o tema fascinante da museologia na sociedade brasileira contemporânea.

Nesses últimos anos temos publicado variados artigos e textos a respeito desse conjunto museológico, analisando também aspectos relacionados à figura literária e poética de Dante Milano. Trabalhos que podem ser consultados para testar a pertinência dessas sugestões e hipóteses interpretativas (CORRÊA, 20092013). Mas, ainda seguindo na direção crítica apontada, e abalando o conservadorismo ${ }^{15}$ dominante e persistente no espaço do patrimônio cultural e da museologia em nosso país e na América Latina (CANCLINI, 2003), utilizamos a obra de outro grande poeta brasileiro para concluir nosso trabalho provocativo.

\section{Museu de Tudo}

Como consideramos urgente fazer uma profunda reflexão sobre metáfora "museu" na cultura e na sociedade brasileira - imbuídos dessa inquietante heterodoxia -utilizarmos um poema de João Cabral de Melo Neto, Museu de tudo, no qual o vate brasileiro condensa de modo muito especial o esforço investigativo apresentado aqui de modo mais prosaico. Assim, se tudo pode ser museologizado - num mundo que cultua cada vez mais a velocidade das mudanças, numa transformação alucinante e devoradora - quando o museu de tudo "é depósito do que aí está", indagamos: por que não poderia existir um "museu mefistofélico"? ${ }^{16}$

O poema Museu de tudo nos indica um novo caminho, talvez mais fecundo - sem contudo deixar de ser irônico - para a futura reflexão sobre a gestão política do teatro das memórias e do patrimônio cultural em nossa sociedade: "Este museu de tudo é museu/como qualquer outro reunido;/como museu, tanto pode ser/caixão de lixo ou arquivo./Assim, não chega ao vertebrado/que deve entranhar qualquer livro:/é depósito do que aí está,/se fez sem risca ou risco" (MElo NETO, 1976). 


\section{NOTAS}

1 Primeira versão deste texto apresentado na 26a․ Reunião Brasileira de Antropologia (RBA), 01 e 04 de junho de 2008, Porto Seguro/BA, Brasil. Mesa redonda 5 - Antropologia dos Objetos, Museus e Cidades Patrimoniais. Uma segunda versão serviu de base para nossa participação como professor/pesquisador convidado no Curso Livre de Folclore e Cultura Popular/CNFCP-2010.

2 Entrevista a Beatriz-Perrone Moisés em Paris, 1998. Folha de S. Paulo, domingo, 27 de junho de 1999, Caderno Mais!, p.7.

3 Rua da Relação n. 42 (continuação da Av. República do Chile, na direção da Rua Henrique Valadares).

4 Observamos um grande potencial turístico reservado a este equipamento cultural, numa época que se dá cada vez importância a questão da violência, na sociedade brasileira. Hoje o Museu da Polícia Civil está hospedado na sede original da 1a à 4a Delegacia da Polícia Civil do Distrito Federal (1912). Prédio Tombado. Nos anos da Ditadura Militar de 1960-70, foi sede do tenebroso DOPS; hospeda também parte dos arquivos da instituição policial.

5 A Comissão Nacional da Verdade (CNV) foi criada pela lei 12528/2011 e instituída em 16 de maio de 2012. A CNV tem por finalidade apurar graves violações de direitos humanos ocorridas entre 18 de setembro de 1946 e 5 de outubro de 1988. Em dezembro de 2013, o mandato da CNV foi prorrogado até dezembro de 2014 pela medida provisória n. 632.

6 Convênio entre a Fundação Nacional da Arte e Conselho Nacional de Direitos Autorais.

7 Figura tão famosa no campo religioso umbandista, que muitos devotos se dirigiam ao museu para oferecer oferendas e reverências à estátua museologizada pela instituição policial.

8 Fausto, no Prólogo: "Do Céu, através do mundo, até o inferno" (GOETHE, 1952).

9 Analogia ingênua entre Mefistófeles e Exu Sete Capas, expressa na ficha identificatória. Peça museológica perdida em incêndio ocorrido na Academia de Polícia em 1989.

10 "A essência da antiga lenda de Fausto consiste no fato de ele ter perdido a noção de seus limites. Cada perda desse tipo é paga com um preço próprio. Conta a história que Fausto era um mago e charlatão que negociou com o Diabo para ganhar poderes sobre-humanos pelo prazo de 24 anos, período após o qual Mefistófeles, um dos sete príncipes do Inferno, vem reivindicar a alma de Fausto para a condenação eterna. A lenda evoluiu ao longo dos últimos cinco séculos, em livros de histórias populares, espetáculos de marionetes, dramas trágicos, poemas, óperas, sinfonias, romances modernos e filmes" (GALL, 2005). 
11 Acervo Missão de Pesquisas Folclóricas, 1938. http://www.centrocultural. sp.gov.br/missao_p.htm

12 A Embratur (Instituto Brasileiro de Turismo) nos anos 70 e 80 implementou ações de "turistificação" com repercussões até hoje no cenário cultural brasileiro.

13 Posição defendida pela antropóloga Yvonne Maggie em recente texto publicado no Blog Raiz Africana, intitulado Arsenal da macumba: “(...) é possível especular que o sumiço da coleção do Museu da Polícia tenha algo a ver com a força crescente das religiões evangélicas no Rio de Janeiro, inimigas mortais da feitiçaria, que têm crentes em todas as esferas da sociedade, até na policial". Texto Disponível: http://raizafricana.wordpress.com/2009/12/16/o-arsenal-da-macumba-por-yvonne-maggie/ Acesso: 7 de maio de 2010.

14 Paródia do título do livro organizado por Patrícia Birman (1997), O mal à brasileira.

15 Precisamente porque o patrimônio cultural se apresenta alheio aos debates sobre a modernidade ele constitui o recurso menos suspeito para garantir a cumplicidade social. Esse conjunto de bens e práticas tradicionais que nos identificam como nação ou como povo é apreciado como um dom, algo que recebemos do passado com tal prestígio simbólico que não cabe discuti-lo. As únicas operações possíveis - preservá-lo, restaurá-lo difundi-lo - são a base mais secreta da simulação social que nos mantém juntos. Frente à magnificência de uma pirâmide maia ou inca, de palácios coloniais, cerâmicas indígenas de três séculos atrás ou à obra de um pintor nacional reconhecido internacionalmente, não ocorre a quase ninguém pensar nas contradições sociais que expressam. A perenidade desses bens leva a imaginar que seu valor é inquestionável e torna-os fontes de consenso coletivo, para além das divisões de classe, etnias e grupos que cindem a sociedade e diferenciam os modos de apropriar-se do patrimônio. Por isso mesmo, o patrimônio é o lugar onde meIhor sobrevive hoje a ideologia dos setores oligárquicos, quer dizer, o tradicionalismo substancialista (CANCLINI, 2003, p. 160).

16 Provocação que se inspira na recorrente, significativa e recalcitrante característica de nossa sociedade, que, se me for permitida a liberdade de uma pequena ironia, é campeã das improvisações socioculturais.

\section{REFERÊNCIAS BIBLIOGRÁFICAS}

ALIGHIERI, Dante. A divina comédia. São Paulo: Nova Cultural, 2003.

BANDEIRA, Manuel. Libertinagem \& Estrela da manhã. Rio de Janeiro: Nova Fronteira, 2000.

BAUDELAIRE, Charles. As flores do mal. São Paulo: Max Limonad, 1981. 
BERMAN, Marshall. Tudo que é sólido desmancha no ar. São Paulo: Companhia das Letras, 1986.

BIRMAN, Patrícia (Org.). O mal à brasileira. Rio de Janeiro: Uerj, 1997.

CANCLINI, Nestor. Culturas híbridas. São Paulo: Edusp. 2003.

CHAIN, Iza G. da Cunha. O diabo nos porões das caravelas: mentalidades, colonialismo e reflexos da constituição da religiosidade brasileira nos séculos XVI e XVII. Campinas: Pontes Editores, 2003.

CLIFFORD, James. A experiência etnográfica. Rio de Janeiro: UFRJ. 1998.

CORRÊA, Alexandre Fernandes. O imaginário do mal no movimento literário brasileiro do início do século XX. Brasil-Europa, v.6, p.122-136, 2009.

CORRÊA, Alexandre Fernandes. A coleção museu de magia negra do Rio de Janeiro: um estudo sobre significado cultural do primeiro tombamento etnográfico no Brasil. Relatório de Estágio de Pós-Doutorado na IFCS/UFRJ. 2006.

. O museu mefistofélico: análise do tombamento do primeiro patrimônio etnográfico do Brasil. Relatório de estágio de pós-doutorado na PPGCS/ UERJ. 2010.

. Dante Milano e o imaginário do mal no modernismo brasileiro. Revista do Arquivo Geral da Cidade do Rio de Janeiro, v.1, p.51-65, 2010.

. Análise cultural do torrão dos infernos: imaginário do mal nas poéticas de Dante Milano e Nauro Machado. Estudos de Literatura Brasileira Contemporânea, v.40, p.213-233, 2012.

. A experiência da poesia do amor em Dante Milano. Psicanálise \& Barroco em Revista, v. 11, p.148-167, 2013.

. Torrão dos infernos: o imaginário do mal em Dante Milano e Nauro Machado. Cadernos de Arte e Antropologia, v.2, p.85-102, 2013.

FOUCAULT, Michel. As palabras e as coisas. São Paulo: Martins Fontes, 1992.

FREYRE, Gilberto. Casa grande \& senzala. Brasília: UNB, 1963.

GALL, Norman. Lula e Mefistófeles. Braudel Papers, n.38, Instituto Fernand Braudel, 2005. http://www.braudel.org.br/

GOETHE, W. Fausto. São Paulo: Brasileira, 1952.

HOLANDA, Sérgio Buarque de. Visão do paraíso. São Paulo: Brasiliense, 2000.

LÉVI-STRAUSS, Claude. O olhar distanciado. Viseu: Edições 70, 1986.

MAGGIE, Yvonne et al. Arte ou magia negra? Relatório Funarte - Convênio CNDA. Rio de Janeiro, (mimeo.), 1979.

. Medo do feitiço. Rio de Janeiro: Arquivo Nacional. 1992.

MARIANO, Ricardo. Igreja universal do reino de deus: a magia institucionalizada. Dossiê Magia. Revista USP/Coordenadoria de Comunicação Social, Universidade de São Paulo, n.31, São Paulo: USP/CCS, 1996.

MELO NETO, João Cabral de. Museu de tudo. Rio de Janeiro: José Olympio, 1976. MERLEAU-PONTY, Maurice. Da realidade sem mistério ao mistério do mundo. São Paulo: Brasiliense. 1981. 
. Textos escolhidos. Coleção Os Pensadores. Rio de Janeiro: Abril Cultural, 1984.

PAVIS, Patrice. A análise dos espetáculos. São Paulo: Perspectiva, 2003.

RAMOS, Arthur. O negro brasileiro. Rio de Janeiro: Graphia, 2001.

RIO, João do. As religiões do Rio. Rio de Janeiro: Garnier, 1906. . As religiões do Rio. Rio de Janeiro: Simões, 1951.

RIMBAUD, Jean-Arthur. Uma temporada no inferno \& iluminações. Rio de Janeiro: Francisco Alves, 1993.

TAUSSIG, Michael. The magic of the state. New York: Routledge, 1997.

. O diabo e o fetichismo da mercadoria na América do Sul. São Paulo: Ed. Unesp, 2010.

VIANNA, Hermano. O mistério do samba. Rio de Janeiro: Jorge Zahar, 1995.

Alexandre Fernandes Corrêa é docente associado IV de sociologia/antropologia da UFRJ Campus Macaé, com doutorado em ciências sociais: antropologia (PUC/ SP) e pós-doutorados em antropologia (UFRJ-2006 e UERJ-2010).

Recebido em: 22/03/2014

Aceito em: 05/04/2014 
